\title{
Reduced Burden of Childhood Diarrheal Diseases through Increased Access to Water and Sanitation in India: A Modeling Analysis
}

\author{
Arindam Nandi \\ Center for Disease Dynamics, Economics \& Policy, 1400 Eye St NW, Ste 500, Washington DC \\ 20005, USA; and Public Health Foundation of India, Gurgaon, India \\ Corresponding author: nandi@,cddep.org \\ Phone: (+1) 202-939-3300 \\ Itamar Megiddo \\ Center for Disease Dynamics, Economics \& Policy, Washington DC, USA; and Department of \\ Management Science, University of Strathclyde, Glasgow, UK \\ megiddo@cddep.org \\ Ashvin Ashok \\ Center for Disease Dynamics, Economics \& Policy, Washington DC, USA \\ ashok@cddep.org \\ Amit Verma \\ Center for Disease Dynamics, Economics \& Policy, Washington DC, USA \\ verma@,cddep.org

\section{Ramanan Laxminarayan} \\ Center for Disease Dynamics, Economics \& Policy, Washington DC, USA; \\ Princeton University, Princeton, NJ, USA; \\ and Public Health Foundation of India, Gurgaon, India \\ ramanan@,cddep.org
}




\section{Abstract}

Each year, more than 300,000 children in India under the age of five years die from diarrheal diseases. Clean piped water and improved sanitation are known to be effective in reducing the mortality and morbidity burden of diarrhea but are not yet available to close to half of the Indian population. In this paper, we estimate the health benefits (reduced cases of diarrheal incidence and deaths averted) and economic benefits (measured by out-of-pocket treatment expenditure averted and value of insurance gained) of scaling up the coverage of piped water and improved sanitation among Indian households to a near-universal 95\% level. We use IndiaSim, a previously validated, agent-based microsimulation platform to model disease progression and individual demographic and healthcare-seeking behavior in India, and use an iterative, stochastic procedure to simulate health and economic outcomes over time. We find that scaling up access to piped water and improved sanitation could avert 43,352 (95\% uncertainty range [UR] 42,20144,504) diarrheal episodes and 68 (95\% UR 62-74) diarrheal deaths per 100,000 under-5 children per year, compared with the baseline. We estimate a saving of (in 2013 US\$) $\$ 357,788$ $(95 \% \$ 345,509-\$ 370,067)$ in out-of-pocket diarrhea treatment expenditure, and \$1,646 (95\% UR $\$ 1,603-\$ 1,689)$ in incremental value of insurance per 100,000 under-5 children per year over baseline. The health and financial benefits are highly progressive, i.e. they reach poorer households more. Thus, scaling up access to piped water and improved sanitation can lead to large and equitable reductions in the burden of childhood diarrheal diseases in India.

Keywords: India; water; sanitation; childhood diarrhea; agent-based model; cost effectiveness; financial risk protection 


\section{Introduction}

Each year, roughly 1.2 million children under the age of five years die in India (You et al., 2015). India accounts for $20 \%$ of the global burden of under-five deaths and is the single largest contributor to this burden (You et al., 2015). Diarrhea is among the leading causes of child death in India, claiming more than 300,000 lives (Liu et al., 2012; Parashar et al., 2003) and resulting in economic losses of $\$ 13$ billion, or $1.5 \%$ of gross domestic product (GDP) per year (UNICEF, 2013). Of pathogens causing diarrheal disease, only rotavirus is currently vaccine-preventable; in India, it causes about $40 \%$ of all diarrhea hospitalizations, 2 million outpatient visits, and 113,000-153,000 child deaths per year (Kang et al., 2005; Morris et al., 2012; Tate et al., 2009). India has recently introduced a vaccine against rotavirus, but non-rotavirus diarrhea will continue to be an important cause of morbidity and mortality (PIB, 2014a).

Access to clean drinking water, sanitation, and hygiene can reduce the incidence of non-rotavirus diarrhea in low- and middle-income countries (Arnold and Colford, 2007; Cairncross et al., 2010; Esrey et al., 1985; Fewtrell et al., 2005; Fink et al., 2011). Using household survey data from 70 developing countries over the period of 1986-2007, Fink et al. (2011) found that access to improved sanitation was associated with a $13 \%$ reduced odds of childhood diarrhea incidence and $27 \%$ reduced odds of stunting. The authors also showed that access to high quality water was associated with $8 \%$ lower odds of diarrhea and $9 \%$ lower odds of stunting. In a meta-analysis of 46 studies across developing countries, Fewtrell et al. (2005) found that access to improved water supply and sanitation reduced the risk of diarrhea morbidity in overall population by $25 \%$ and $32 \%$, respectively, while access to water and sanitation together reduced the risk by $33 \%$. 
In India, Jalan and Ravallion (2003) used nationally representative household survey data from the National Council of Applied Economic Research of India (1993-1994) and employed quasiexperimental matching methods to find that access to piped water reduced the prevalence of diarrhea among children by $17.4 \%$. Similarly, Kumar and Vollmer (2013) used matching methods on the District Level Household Survey 2007-2008, another large nationally representative database, to find that children with access to improved sanitation were $16.9 \%$ less likely to contract diarrhea compared with similar children with no access.

The World Health Organization (WHO) and the United Nations Children's Fund (UNICEF) recommend a seven-point plan that includes both prevention and treatment strategies for tackling childhood diarrhea (WHO/UNICEF, 2009). Three of these seven strategies are related to hygiene ("Promotion of handwashing with soap"), clean water ("Improved water supply quantity and quality, including treatment and safe storage of household water"), and sanitation ("Communitywide sanitation promotion").

The United Nations Millennium Development Goal (MDG) target 7c aimed to reduce by half "the proportion of the population without sustainable access to safe drinking-water and basic sanitation" across the world by 2015. Later, the goal was modified to consider "improved" drinking water, which included piped water, public tap water, tube wells and boreholes, protected wells, and protected spring and rainwater collection. The newly adopted United Nations Sustainable Development Goal number 6 has called for "universal and equitable access to safe and affordable drinking water" and "adequate and equitable sanitation and hygiene for all” by 2030 (UN, 2015). 
According to the 2011 MDG report, more than $90 \%$ of Indian households now have access to improved drinking water (UNDP, 2011). However, the estimates are based on self-reported sources of drinking water and do not consider its actual quality. "Improved" drinking water may not necessarily be free from contaminants and pathogens (Bain et al., 2012). A recent study in urban India found that among households who reported using at least one method of water purification at home, more than 55\% had fecal bacteria contamination in their drinking water (Jalan and Somanathan, 2008). Therefore, further improvements in access to clean water could reduce the burden of diarrheal diseases.

Although most Indian households have access to improved drinking water, close to half still lack access to basic sanitation (UNDP, 2011), and only 40\% have access to "improved" sanitation (defined by WHO/UNICEF as certain types of flush, pit, or composting toilet) (WB, 2015; WHO and UNICEF, 2000). In 1999, India launched the "Total Sanitation Campaign," which built more than 64.3 million toilets by 2010 , increasing sanitation coverage significantly over a decade (WB, 2010). The campaign, which cost approximately US\$25 per household in 2009 (Kumar and Vollmer, 2013), focused on providing access to toilets and encouraging their use. It was expanded into a larger sanitation and public health program named the Swachh Bharat (Clean India) Mission in 2014, with a goal of providing universal access to sanitation by 2019. During 2014-2015, Swachh Bharat Mission has built 5.85 million new toilets across rural India (GoI, 2015).

In this study, we estimate the potential health and economic benefits of scaling up access to piped drinking water (for individual households or via public taps) and improved sanitation (flush or pit toilet) in India using IndiaSim, an agent-based microsimulation model that is based on a representative population. IndiaSim incorporates individual characteristics related to 
demographic and healthcare-seeking behavior, aggregate disease progression, and characteristics of the public healthcare delivery system (Megiddo et al., 2016, 2014a, 2014b; Nandi et al., 2016). We estimate the extent to which scaling up the combined coverage of piped water and improved sanitation to a near-universal, $95 \%$ level would reduce the health and economic burden of childhood diarrheal diseases. Health benefits are reflected by changes in incidence of diarrheal disease and deaths averted compared with a baseline of current coverage. Economic benefits are measured by changes in out-of-pocket expenditure for diarrheal disease treatment that is averted, and the extent of financial risk protection offered by the interventions.

\section{Materials and methods}

IndiaSim is programmed in $\mathrm{C}++11$ standard and $\mathrm{R}$ version 3.2 ( $\mathrm{R}$ Core Team, 2015). It is an iterative, stochastic model, where each model iteration represents a day (the time-step of the model). The model is organized in the form of geographical units, or patches. The urban and rural regions of Indian states and union territories are modeled as patches where each patch encompasses a set of households. These households consist of individuals representative of the respective rural or urban population in the given state.

\subsection{Demographic data}

The population data underlying IndiaSim come from the District Household Survey (DLHS-3) of 2007-2008 of India. DLHS-3 is a large-scale cross-sectional household survey of 720,000 households (more than 3.7 million individuals) from 601 districts in India that collected information on household socioeconomic characteristics, demographics, indicators of healthseeking behavior, and household access to water supply and sanitation. These data are publicly available and a separate ethics clearance was not required for this study. We populate the model 
utilizing demographic (age and gender) data of approximately 750,000 individuals from 131,000 randomly selected households from DLHS-3.

\subsection{Income data}

Households in IndiaSim are categorized by wealth quintile based on a composite index of asset ownership and living conditions (Filmer and Pritchett, 2001). We obtained data on GDP per capita at national and state levels from the World Bank and the Government of India (GoI, 2013; WB, 2015). We extrapolate the wealth index to create a distribution of per capita GDP (and five quintiles) across the population, which is then used to estimate the financial risk protection gained from the interventions.

\subsection{Disease and treatment data}

Individuals in IndiaSim are classified as healthy or suffering from diarrheal disease. They contract diarrheal pathogens based on a stochastic function of their characteristics (age and gender) and access to drinking water and sanitation. We use data from published studies to determine incidence by age (Fischer Walker et al., 2012) and case fatality rate (Black et al., 2014) of diarrheal diseases among the target population of under-five children, as shown in Table 1. In our model, access to piped water and improved sanitation only affects the incidence of diarrheal diseases. Case fatality, which is the likelihood of death for an incident case of diarrheal diseases, depends on the extent of dehydration and fluid loss from diarrhea (Bhandari et al., 1992; WHO, 2013). Since the effect of piped water and improved sanitation on these is not clear, we conservatively assume the case fatality rate to be the same in baseline and intervention scenarios. Those suffering from diarrheal diseases are assumed to seek treatment based on their 
wealth quintile-specific average treatment demand rates. Using data from the 60 th round of the National Sample Survey of India (2004), we calculate treatment demand as the proportion of people suffering from diarrhea who sought treatment (self-reported by survey respondents) during 15 days preceding the survey. We assume that treatment demand is the same across all simulation scenarios.

The share of patients receiving inpatient or outpatient care, choice between public or private healthcare provider, and costs of treatment are also from the National Sample Survey 60th round data. For these indicators, we use wealth quintile-specific estimates when data are available. We assume that treatment for diarrheal diseases, which is primarily oral rehydration therapy (alternatively antibiotics, when prescribed, or inpatient care, if required, or a combination of these), is universally available at public or private healthcare facilities — anyone who demands treatment at the point of care will be able to receive it (Wilson et al., 2013). We do not model for treatment efficacy. It is implicitly incorporated and assumed to be the same across baseline and intervention scenarios.

\subsection{Water supply and sanitation data}

Water supply and sanitation facilities come in various forms (Hutton and Bartram, 2008; Hutton and Haller, 2004; WHO and UNICEF, 2000). For this study, we consider piped water supply, defined as access either via a tap in the household premises or from a public tap nearby. For improved sanitation, we consider a household's access to a public sewer, septic system, pourflush latrine, simple pit latrine, or ventilated improved pit latrine. We obtain the per capita costs of scaling up various water and sanitation facilities from previous studies (Hutton, 2013, 2012). 
Data on access to piped water supply and improved sanitation for each household in the baseline model are from DLHS-3. In the simulations, we assume that households that previously had access to these facilities in DLHS-3 continue to have access in years following the survey. In intervention scenarios, additional households are randomly assigned with access to piped water and improved sanitation in a way such that the distribution of these facilities within each wealth quintile as in the baseline is preserved. For the lowest wealth quintile with almost no coverage of sanitation, the cheapest form of sanitation (simple pit or ventilated improved pit) is assigned to households in the intervention scenarios.

We project outcomes under two interventions. In intervention 1, the coverage rates of piped water and improved sanitation are separately increased across all Indian households randomly to a $95 \%$ level. This results in $91 \%$ of households gaining access to both piped water and improved sanitation. The remaining $9 \%$ of households receive access to either piped water alone or improved sanitation alone, or neither. In intervention 2 , the coverage rates of piped water and improved sanitation are increased to at least 95\% level separately within each state. In addition to variations in population demographics and economic status, the baseline coverage of piped water and improved sanitation across states is also different. Intervention 1 would likely benefit the more populous states, which also have lower baseline coverage rates, more. In comparison, scaling the coverage up to $95 \%$ within each state separately would produce more geographically equitable outcomes than scaling up randomly across the nation. Intervention 2 is equivalent to providing $92 \%$ of Indian households with access to both piped water and improved sanitation. 
The efficacy of the interventions in reducing the incidence of childhood diarrheal diseases are from published studies. In the absence of nationally representative data from India on the joint efficacy of water and sanitation, we draw efficacy estimates from a large multi-country metaanalysis (Fewtrell et al., 2005). We assume that access to both piped water and improved sanitation would jointly reduce the relative risk of children's contracting diarrheal diseases by $33 \%$, while access to piped water alone and improved sanitation alone would reduce the risk by $25 \%$ and $32 \%$ respectively (Fewtrell et al., 2005). We incorporate the uncertainty in efficacy rates through a systematic sensitivity analysis (see Analysis section). Tables 2 and 3 present data the on treatment and intervention parameters used in our model.

The level of interdependency between the effects of water and sanitation on childhood diarrheal diseases is unclear, especially in the context of India. Hence, we consider an alternative scenario is which the efficacy rates of access to piped water and improved sanitation are independent and $25 \%$ and $32 \%$ respectively (Fewtrell et al., 2005). In this case, we assume the combined efficacy for households with access to both to be [1-(1-efficacy of piped water $) \times(1-$ efficacy of improved sanitation)].

We consider a final alternative scenario in which the efficacy rates are drawn from India based studies. There is considerable debate surrounding the efficacy of sanitation in reducing childhood diarrhea in India. Two recent trials in the states of Odisha and Madhya Pradesh found no effect of sanitation access on diarrhea rates, possibly because of partial uptake of sanitation and low usage rates, and similar levels of access to clean water in intervention and control areas (Clasen et al., 2014; Patil et al., 2014). However, another study in Odisha reported that a water and sanitation intervention that increased latrine use rates could reduce diarrhea episodes by $30 \%-$ $50 \%$ for a period of up to five years (Duflo et al., 2015). 
Because small-scale community-based studies are unlikely to provide externally valid estimates, we use efficacy data from two nationally representative studies of water and sanitation (Jalan and Ravallion, 2003; Kumar and Vollmer, 2013). We assume that these efficacy rates are independent, and that the combined efficacy for households with access to both is [1-(1-efficacy of piped water) $\times(1-$ efficacy of improved sanitation $)]$.

\subsection{Analysis}

The baseline model (with DLHS-3 coverage levels) and interventions (with 95\% coverage levels) are simulated for a period of six years. A burn period of the first five years in each simulation is executed such that the prevalence of diarrheal diseases among under-five children reaches an equilibrium level. Results from year 6 of each simulation are analyzed in R and presented here.

We estimate the following outcomes. Health benefits of the interventions are measured by the number of diarrheal disease episodes and deaths among under-five children that are averted from the baseline. Economic benefits are measured by the averted out-of-pocket treatment expenditure due to lower diarrheal disease incidence, and financial risk protection, as measured by the incremental money-metric value of insurance (Verguet et al., 2014). The money-metric value of insurance is equivalent to the 'risk premium'- the sum households would be willing to pay to avoid the financial risk associated with childhood diarrheal diseases.

To capture the uncertainty in the values of our input parameters, we conduct a Latin Hypercube Sampling (LHS) sensitivity analysis. We use LHS over other methods of sampling since it stratifies the underlying distribution of parameters and makes the generated sample more representative, thereby requiring fewer iterations (Iman and Helton, 1988; Marino et al., 2008; McKay et al., 1979). We vary the input parameter values within a range of $70 \%-130 \%$ (see 
Tables 1-3 in the appendix) and simulate each intervention 100 times. The results are then used to construct $95 \%$ uncertainty range for the mean health and economic benefits obtained from our analysis.

\section{Results}

Households in the DLHS-3 baseline have $35 \%$ and $36 \%$ coverage of piped water and improved sanitation, respectively. There is substantial variation in coverage across states, however (see

Figures 1 and 2). Coverage of piped water ranges from $2 \%$ in Bihar to $96 \%$ in Chandigarh, and is less than $15 \%$ in the poorer and larger states of Uttar Pradesh, Bihar, Jharkhand, Chhattisgarh, Odisha, and Assam. In comparison, Arunachal Pradesh, Daman \& Diu, Tamil Nadu, and Sikkim have piped water coverage rates of $85 \%$ or higher. Similarly, improved sanitation coverage varies from $13 \%$ in Odisha to $99 \%$ in Lakshadweep. Seven poorer states, Jharkhand, Bihar, Chhattisgarh, Madhya Pradesh, Jammu \& Kashmir, Rajasthan, and Uttar Pradesh all have improved sanitation coverage rates of less than 25\%. In comparison, Sikkim, Delhi, Mizoram, Kerala, and Chandigarh have improved sanitation coverage rates of $80 \%$ or higher. Some states, such as Tamil Nadu and Kerala, do well in only one of the measures: Tamil Nadu has a high level of piped water but relatively low improved sanitation coverage, and vice versa for Kerala.

Table 4 presents the annual incremental health benefits of scaling up piped water and improved sanitation, compared with the baseline. We find that intervention 1 would avert 43,126 (95\% uncertainty range [UR] 42,085-44,167) diarrheal disease episodes and 68 (95\% UR 61-74) deaths per 100,000 under-five children annually. Intervention 2 would avert 43,352 (95\% UR 42,201-44,504) diarrheal episodes and 68 (95\% UR 62-74) deaths per 100,000 under-five 
children annually. Both interventions are highly progressive - they preferentially benefit the poor, and the benefit gradually reduces across higher wealth quintiles. Under both interventions, the number of diarrheal disease episodes averted among children in the poorest wealth quintile is almost 20 times as much as the episodes averted in the highest wealth quintile. The number of deaths averted ranges from 105 (95\% UR 91-118) to 10 (95\% UR 0-24) per 100,000 in the lowest to highest quintiles in intervention 1, and from 113 (95\% UR 101-126) to 11 (95\% UR 021) per 100,000 children under intervention 2 .

The annual incremental economic benefits of the interventions over baseline, measured in 2013 US\$, are presented in Table 5. We find that intervention 1 could save \$355,681 (95\% UR $\$ 344,374-\$ 366,987)$ in out-of-pocket treatment expenditure for diarrheal diseases per 100,000 under-five children, and intervention 2 could avert \$357,788 (95\% UR \$345,509-\$370,067) in out-of-pocket costs. The out-of-pocket expenditure averted is also highly progressive across wealth quintiles. The population in the lowest wealth quintile experiences the maximum out-ofpocket cost averted, at $\$ 586,765$ (95\% UR \$568,419-\$605,111) and \$596,952 (95\% UR $\$ 576,967-\$ 616,936)$ per 100,000 under-five children in interventions 1 and 2, respectively. In comparison, those in the highest wealth quintile avert out-of-pocket costs of $\$ 36,530$ (95\% UR $\$ 27,087-\$ 45,973)$ and $\$ 33,799$ (95\% UR \$25,231-\$42,367), respectively.

The annual costs of scaling up piped water and improved sanitation under interventions 1 and 2 are $\$ 4.03$ million (95\% UR \$3.95 million- $\$ 4.11$ million) and $\$ 3.90$ million (95\% UR $\$ 3.82$ million-\$3.97 million) per 100,000 under-five children, respectively. The cost of scaling up the intervention per 100,000 ranges from $\$ 1.47$ million (95\% UR \$1.38 million-\$1.56 million) for the highest wealth quintile to $\$ 3.20$ million (95\% UR \$3.14 million-\$3.25 million) for the lowest 
quintile under intervention 1. In intervention 2, scaling up cost ranges from $\$ 1.57$ million (95\% UR \$1.48 million-\$1.66 million) for the richest quintile to \$3.30 million (95\% UR \$3.24 million-\$3.35 million) for the poorest quintile. In both cases, the cost is highest in the second wealth quintile.

The annual incremental value of insurance gained under intervention 1 over baseline is $\$ 1,640$ (95\% UR \$1,598-\$1,681) per 100,000 under-five children, while it is marginally higher for intervention 2 at $\$ 1,646(95 \%$ UR $\$ 1,603-\$ 1,689)$. The financial protection afforded over wealth quintiles shows a highly progressive trend, with the poorest quintile gaining risk protection of as much as $\$ 7,125$ (95\% UR \$6,950-\$7,301) and \$7,185 (95\% UR \$7,002-\$7,367) for interventions 1 and 2, respectively, whereas the richest gain \$64 (95\% UR \$54-\$73) and \$66 (95\% UR \$57\$74), respectively.

The state-wise distribution of the health and economic benefits of the interventions is presented in Figures 3 and 4. Uttar Pradesh, Madhya Pradesh, Bihar, Jharkhand, Odisha, and Chhattisgarh receive the highest health benefits, with at least 50,000 diarrheal disease episodes and 60 deaths averted per 100,000 under-five children per year in each state under either intervention scenario. These states also experience the highest reductions in out-of-pocket expenditure of at least $\$ 425,000$ per 100,000 , and have the highest incremental money-metric value of insurance of at least $\$ 3,500$ per 100,000 in either intervention. With respect to the health and economic benefits received by the states, intervention 2 is more progressive than intervention 1. For example, the six states mentioned above avert an average of 946 more diarrheal disease episodes and $\$ 9,686$ in out-of-pocket treatment expenditure per 100,000 under intervention 2, compared with intervention 1. 
If we consider the alternative scenario with independent piped water and improved sanitation efficacy rates drawn from Fewtrell et al. (2005), intervention 1 would avert 69,342 (95\% UR 68,086-70,597) diarrheal disease episodes, 89 (95\% UR 82-96) deaths, and \$578,388 (95\% UR $\$ 562,915-\$ 593,861)$ in out-of-pocket expenditure, and provide $\$ 2,562$ (95\% UR \$2,512-\$2,612) in incremental value of insurance per 100,000 under-five children. In comparison, intervention 2 would avert 70,615 (95\% UR 69,373-71,856) diarrheal disease episodes, 93 (95\% UR 86-100) deaths, and $\$ 589,026$ (95\% UR $\$ 573,241-\$ 604,812$ ) in out-of-pocket expenditure, and provide $\$ 2,592$ (95\% UR \$2,541-\$2,643) in incremental value of insurance per 100,000 under-five children.

Finally, if we use India-specific efficacy rates of $17.4 \%$ for piped water (Jalan and Ravallion, 2003 ) and $16.9 \%$ for improved sanitation (Kumar and Vollmer, 2013), intervention 1 would avert 44,653 (95\% UR 43,596-45,711) diarrheal disease episodes, 61 (95\% UR 55-68) deaths, and $\$ 373,414$ (95\% UR $\$ 362,824-\$ 384,004$ ) in out-of-pocket expenditure, and provide $\$ 1,734$ (95\% UR \$1,690-\$1,778) in incremental value of insurance per 100,000 under-five children. In comparison, intervention 2 would avert 45,380 (95\% UR 44,291-46,470) diarrheal disease episodes, 65 (95\% UR 59-72) deaths, and \$378,297 (95\% UR \$367,312-\$389,282) in out-ofpocket expenditure, and provide $\$ 1,759(95 \%$ UR $\$ 1,712-\$ 1,805)$ in incremental value of insurance per 100,000 under-five children.

\section{Discussion}

There is a close relationship between the provision of water and sanitation. Diarrheal diseases are associated with lack of clean water or sanitation, and generally originate from fecal pathogens. 
Inadequate sanitation then helps transmit the pathogens into drinking water (Fewtrell et al., 2005; Kumar and Vollmer, 2013). Therefore, large reductions in the burden of childhood diarrheal diseases will be possible only with sweeping improvements in access to both water and sanitation.

We estimate that among the 112.6 million under-five children in India (as per 2011 census) (GoI, 2011), scaling up access to piped water and improved sanitation could avert 48.8 million episodes of childhood diarrheal diseases and 76,574 related deaths, and avoid $\$ 402.9$ million in related out-of-pocket treatment expenditure at a cost of $\$ 4.5$ billion. Three states - Uttar Pradesh, Bihar, and Madhya Pradesh - contribute the most, with a total of 23.3 million diarrheal disease episodes, 33,884 deaths, and $\$ 191.8$ million in out-of-pocket treatment expenditure averted at a cost of $\$ 2.1$ billion. The benefits are progressive, with individuals belonging to lower income groups or poorer states gaining the most.

Our results can be used for a multi-criteria comparison of the benefits of water and sanitation with benefits from other child health interventions. For example, a recent study has estimated that introducing a rotavirus vaccine in India (with a coverage of 76.8\%) would avert 34.7 deaths and 995 million disability-adjusted life years (DALYs) and \$232,354 in out-of-pocket treatment expenditure from rotavirus per 100,000 under-five children per year (Megiddo et al., 2014a). The authors also estimate that the vaccine would avert \$2.3 million in out-of-pocket treatment expenditure and provide $\$ 23,500$ in annual value of insurance for a cohort of a million under-five children. Another study estimated that universal coverage of a rotavirus vaccine would save $\$ 1.8$ million in out-of-pocket expenditure over the first five years of life and provide $\$ 16,000$ in value of insurance to 1 million Indian households (Verguet et al., 2013). 
If we consider only the cost to government of supplying piped water and improved sanitation facilities (without considering averted out-of-pocket expenditure), intervention 1 costs $\$ 93$ per episode averted, and intervention 2 costs $\$ 90$ per episode averted from the baseline. If averted out-of-pocket expenditure is incorporated, the costs per episode averted would be $\$ 85$ and $\$ 81$, respectively. In comparison, a rotavirus vaccine priced at $\$ 1$ per dose would cost $\$ 21.41$ per DALY averted or $\$ 662.94$ per death averted (Esposito et al., 2011), or could even be cost-saving (Megiddo et al., 2014a) in India.

To put our results in context, it is important to understand the barriers to providing good-quality drinking water. There are few data on the variations in drinking water quality across India. Although the WHO/UNICEF definitions of "safe" or "improved" sources of water provide a benchmark, water quality from the same type of source (e.g., public tap) is likely to vary, by location. Bain et al. (2012) studied drinking water in five developing countries and found that the quality of water may be overestimated. In India, more than $60 \%$ of tap water samples in two large cities, Gurgaon and Kolkata, have tested positive for fecal bacteria in recent studies (Jalan and Somanathan, 2008; Mckenzie and Ray, 2005).

Furthermore, providing piped water is a challenging task. A recent World Bank report found massive financial and physical leakages in urban piped water distribution systems and determined that the average rate of cost recovery was as low as $11 \%$ in Haryana (World Bank, 2012). Delhi, the capital city of India, was recently found to experience almost $40 \%$ transmission and distribution losses in its water supply (ICED, 2008). In many Indian cities, piped water supply is not continuous or pressurized and thus susceptible to possible contamination from pathogens (Jalan and Somanathan, 2008). 
The government of India has recently taken bold steps toward strengthening rural and urban piped water supply. The Jawaharlal Nehru National Urban Renewal Mission (JNNURM) of 2005, an umbrella policy for improving access to public goods and quality of life in urban India, has allocated $70 \%$ of its $\$ 12$ billion budget to water supply and sewerage (WB, 2012). In early 2014, the World Bank extended $\$ 500$ million in credit to the Indian government for strengthening rural water supply and sanitation in Assam, Bihar, Jharkhand, and Uttar Pradesh, four states that rank the lowest in terms of providing piped water in rural areas (WB, 2014). These large-scale projects mark a gradual shift from providing access to "safe" or "improved" but varied sources of water to a more uniform piped water distribution system in India.

Access to toilets may not necessarily imply that the households are using these toilets. Lack of knowledge and hard-to-change behavioral patterns could hinder the use of toilet facilities (Kumar and Vollmer, 2013; UNICEF, 2012). In a recent study by UNICEF in Tamil Nadu, almost $90 \%$ of respondents reported that they were "habituated" to open defecation, and $50 \%$ considered it a cleaner practice than using toilets (UNICEF, 2012). Another new survey in Bihar, Haryana, Madhya Pradesh, Rajasthan, and Uttar Pradesh has found that among households which had access to a working latrine, $40 \%$ reported at least one member to be defecating in the open (Gupta et al., 2014). Two other recent studies have also pointed out that access to sanitation may have a lower-than-expected effect on childhood diarrhea rates because of lack of use (Clasen et al., 2014; Patil et al., 2014).

The government's response to the problem of low sanitation usage has remained inadequate. The 2015-2016 Indian central budget allocated INR 36.25 billion ( $\$ 558$ million, assuming $\$ 1=$ INR 65) to Swachh Bharat Mission (CPR, 2015). However, most of this budgeted amount was earmarked for building new toilets and only $8 \%$ was allocated for information, education and 
communication activities (PIB, 2014b). Without stronger and more frequent educational campaigns, the gap between toilet access and use will be difficult to close in the near future. It is estimated that a universal coverage of latrines would not make any difference particularly in large states such as Bihar, Uttar Pradesh, and Rajasthan (Gupta et al., 2014). Due to lack of knowledge about the benefits of toilets, most people in these states would continue to defecate in the open (Gupta et al., 2014).

The Indian government has also announced that the Swachh Bharat Mission would start monitoring the use of toilets starting in early 2015 (PIB, 2015). Under this new initiative, local officials will use their smartphones and tablet computers to collect and transmit toilet usage data to a central Ministry of Drinking Water and Sanitation database. Information on the coverage or effectiveness of this real-time monitoring initiative are not available yet.

The Total Sanitation Campaign and the recent Swachh Bharat Mission are focused on household-level access and use of toilets, but there also remains a dire need for a comprehensive national sewage treatment program. The United Nations Sustainable Development Goal number 6 has deeply emphasized the need to "improve water quality by reducing pollution, eliminating dumping and minimizing release of hazardous chemicals and materials, halving the proportion of untreated wastewater and substantially increasing recycling and safe reuse globally" (UN, 2015). A 2008 report by the Central Pollution Control Board of the Indian government estimated that only $35 \%$ of the sewage generated from 908 large and medium-sized towns in India was treated (CPCB, 2009). Municipalities in India had a combined capacity to treat less than a third of the 38,000 million liters of sewage generated per day, and about $39 \%$ of the treatment plants did not adhere to standards prescribed by environmental protection legislation (UNICEF, 2013). 
Individual access to sanitation can reduce the burden of diarrheal diseases only if it is combined with proper sewage management that reduces the risk of disease transmission.

Our results are subject to important caveats. We are limited by the availability of data to estimate model parameters, and are unable to consider potential regional differences in many disease, intervention, and treatment parameters. Interstate variations in outcomes are mainly driven by differences in population structure and baseline intervention coverage rates. Also, some input parameters are from older data and may not fully represent the current scenario in India. Second, we do not model for the demand for treatment. Instead, we estimate wealth quintile specific average demand for treatment from self-reported household survey data. We also assume that treatments for diarrheal diseases are universally available at public or private healthcare providers, although the uptake rates may vary regionally (Wilson et al., 2013). These initial assumptions, considered to be the same in baseline and intervention scenarios, might affect our findings. Finally, we do not model the infectious disease dynamics of diarrheal diseases, and therefore, secondary benefits of interventions through reduced transmission of diarrheal pathogens are not captured.

There is considerable disparity in piped water supply and improved sanitation provision across wealth quintiles and states in India. Our analysis, which is based on available evidence on the effectiveness of these facilities in reducing diarrheal incidence and mortality, reveals that interventions to cover households with these facilities would bring significant health and economic benefits to under-five children. Providing access to such facilities would be undoubtedly costly, but the widespread benefits highlight the urgent need to meet this challenge. 



\section{References}

Arnold, B.F., Colford, J.M., 2007. Treating water with chlorine at point-of-use to improve water quality and reduce child diarrhea in developing countries: a systematic review and metaanalysis. The American Journal of Tropical Medicine and Hygiene 76, 354-64.

Bain, R., Gundry, S., Wright, J.A., Yang, H., Pedley, S., Bartram, J., 2012. Accounting for water quality in monitoring access to safe drinking-water as part of the Millennium Development Goals: lessons from five countries. Bulletin of the World Health Organization 90, 228-235. doi:10.2471/BLT.11.094284

Bhandari, N., Bhan, M., Sazawal, S., 1992. Mortality associated with acute watery diarrhea, dysentery and persistent diarrhea in rural north India. Acta Paediatrica 81, 3-6.

Black, R.E., Walker, C.L.F., Lanata, C.F., 2014. Chapter 20: Diarrheal Diseases, in: Nelson, K.E., Williams, C.M. (Eds.), Infectious Disease Epidemiology: Theory and Practice. Jones \& Bartlett Learning, pp. 613-627.

Cairncross, S., Hunt, C., Boisson, S., Bostoen, K., Curtis, V., Fung, I.C.H., Schmidt, W.-P., 2010. Water, sanitation and hygiene for the prevention of diarrhoea. International Journal of Epidemiology 39 Suppl 1, i193-205. doi:10.1093/ije/dyq035

Clasen, T., Boisson, S., Routray, P., Torondel, B., Bell, M., Cumming, O., Ensink, J., Freeman, M., Jenkins, M., Odagiri, M., Ray, S., Sinha, A., Suar, M., Schmidt, W.-P., 2014.

Effectiveness of a rural sanitation programme on diarrhoea, soil-transmitted helminth infection, and child malnutrition in Odisha, India: a cluster-randomised trial. The Lancet Global Health 2, e645-e653. doi:10.1016/S2214-109X(14)70307-9

CPCB, 2009. Status of Water Supply, Wastewater and Generation and Treatment in Class-I Cities and Class-II of India. Central Pollution Control Board, Government of India.

CPR, 2015. The Swachh Bharat Mission, Budget Briefs. Accountability Initiative, Centre for Policy Research, New Delhi. doi:10.1007/s13398-014-0173-7.2

Duflo, E., Greenstone, M., Guiteras, R., Clasen, T., 2015. The Short and Medium Term Impacts of Household Water Supply and Sanitation on Diarrhea in Rural India. Maryland Population Research Center Working paper PWP-MPRC-2015-008 26.

Esposito, D.H., Tate, J.E., Kang, G., Parashar, U.D., 2011. Projected impact and costeffectiveness of a rotavirus vaccination program in India, 2008. Clinical infectious diseases : an official publication of the Infectious Diseases Society of America 52, 171-7. doi:10.1093/cid/ciq094

Esrey, S.A., Feachem, R.G., Hughes, J.M., 1985. Interventions for the control of diarrhoeal diseases among young children: improving water supplies and excreta disposal facilities. Bulletin of the World Health Organization 63, 757-72.

Fewtrell, L., Kaufmann, R.B., Kay, D., Enanoria, W., Haller, L., Colford, J.M., 2005. Water, sanitation, and hygiene interventions to reduce diarrhoea in less developed countries: a 
systematic review and meta-analysis. The Lancet Infectious Diseases 5, 42-52. doi:10.1016/S1473-3099(04)01253-8

Filmer, D., Pritchett, L.H., 2001. Estimating wealth effects without expenditure data-or-tears: An application to educational enrollments in States of India. Demography 38, 115-132.

Fink, G., Günther, I., Hill, K., 2011. The effect of water and sanitation on child health: evidence from the demographic and health surveys 1986-2007. International Journal of Epidemiology 40, 1196-204.

Fischer Walker, C.L., Perin, J., Aryee, M.J., Boschi-Pinto, C., Black, R.E., 2012. Diarrhea incidence in low- and middle-income countries in 1990 and 2010: a systematic review. BMC Public Health 12, 220. doi:10.1186/1471-2458-12-220

GoI, 2015. Swachh Bharat Mission (Gramin) . Ministry of Drinking Water and Sanitation. URL http://tsc.gov.in/TSC/NBA/NBAHome.aspx (accessed 10.14.15).

GoI, 2013. Statewise Per Capita a Income and Gross Domestic Product at current prices. . Government of India. URL https://data.gov.in/keywords/national-income-and-production (accessed 10.15.15).

GoI, 2011. Census of India 2011 . URL http://www.censusindia.gov.in/2011census/population_enumeration.aspx (accessed 5.20.16).

Gupta, A., Spears, D., Coffey, D., Khurana, N., Srivastav, N., Hathi, P., Vyas, S., 2014. Revealed Preference for Open Defecation - Evidence from a New Survey in Rural North India. Economic and Political Weekly 49, 43-55.

Hutton, G., 2013. Global costs and benefits of reaching universal coverage of sanitation and drinking-water supply. Journal of Water and Health 11, 1-12.

Hutton, G., 2012. Global costs and benefits of drinking-water supply and sanitation interventions to reach the MDG target and universal coverage. World Health Organization, Geneva.

Hutton, G., Bartram, J., 2008. Regional and global costs of attaining the water supply and sanitation target (Target 10) of the Millennium Development Goals, OMS, Genève. World Health Organization, Geneva.

Hutton, G., Haller, L., 2004. Evaluation of the costs and benefits of water and sanitation improvements at the global level. World Health Organization, Geneva.

ICED, 2008. Report on Government of NCT of Delhi: Chapter III. International Centre for Environment Audit and Sustainable Development, India.

IIPS, 2010. District Level Household and Facility Survey (DLHS-3), 2007-08. IIPS, International Institute of Population Sciences, Mumbai, India.

Iman, R., Helton, J., 1988. An investigation of uncertainty and sensitivity analysis techniques for computer models. Risk Analysis 8, 71-90.

Jalan, J., Ravallion, M., 2003. Does piped water reduce diarrhea for children in rural India? Journal of Econometrics 112, 153-173. doi:10.1016/S0304-4076(02)00158-6 
Jalan, J., Somanathan, E., 2008. The importance of being informed: Experimental evidence on demand for environmental quality. Journal of Development Economics 87, 14-28.

Kang, G., Kelkar, S.D., Chitambar, S.D., Ray, P., Naik, T., 2005. Epidemiological profile of rotaviral infection in India: challenges for the 21st century. The Journal of Infectious Diseases 192 Suppl, S120-6. doi:10.1086/431496

Kumar, S., Vollmer, S., 2013. Does access to improved sanitation reduce childhood diarrhea in rural India? Health Economics 22, 410-27. doi:10.1002/hec.2809

Lamberti, L.M., Fischer Walker, C.L., Black, R.E., 2012. Systematic review of diarrhea duration and severity in children and adults in low- and middle-income countries. BMC Public Health 12, 276.

Liu, L., Johnson, H.L., Cousens, S., Perin, J., Scott, S., Lawn, J.E., Rudan, I., Campbell, H., Cibulskis, R., Li, M., Mathers, C., Black, R.E., 2012. Global, regional, and national causes of child mortality: an updated systematic analysis for 2010 with time trends since 2000 . The Lancet 6736, 1-11. doi:10.1016/S0140-6736(12)60560-1

Marino, S., Hogue, I.B., Ray, C.J., Kirschner, D.E., 2008. A methodology for performing global uncertainty and sensitivity analysis in systems biology. Journal of Theoretical Biology 254, 178-96. doi:10.1016/j.jtbi.2008.04.011

McKay, M.D., Beckman, R.J., Conover, W.J., 1979. Comparison of Three Methods for Selecting Values of Input Variables in the Analysis of Output from a Computer Code. Technometrics 21, 239-245. doi:10.1080/00401706.1979.10489755

Mckenzie, D., Ray, I., 2005. Household Water Delivery Options in Urban and Rural India (No. 24). Stanford Center for International Development, Stanford University.

Megiddo, I., Colson, A., Chisholm, D., Dua, T., Nandi, A., Laxminarayan, R., 2016. Health and economic benefits of public financing of epilepsy treatment in India: An agent-based simulation model. Epilepsia 57, 464-474. doi:10.1111/epi.13294

Megiddo, I., Colson, A.R., Nandi, A., Chatterjee, S., Prinja, S., Khera, A., Laxminarayan, R., 2014a. Analysis of the Universal Immunization Programme and Introduction of a Rotavirus Vaccine in India with IndiaSim. Vaccine 32, 151-161. doi:10.1016/j.vaccine.2014.04.080

Megiddo, I., Nandi, A., Ashok, A., Prabhakaran, D., Laxminarayan, R., 2014b. Estimating the Health and Economic Benefits of Secondary Prevention of Coronary Heart Diseases in India, DCPN working papers. Center for Disease Dynamics, Economics \& Policy Working Paper.

Morris, S.K., Awasthi, S., Khera, A., Bassani, D.G., Kang, G., Parashar, U.D., Kumar, R., Shet, A., Glass, R.I., Jha, P., 2012. Rotavirus mortality in India: estimates based on a nationally representative survey of diarrhoeal deaths. Bulletin of the World Health Organization 90, 720-7. doi:10.2471/BLT.12.101873

Nandi, A., Colson, A.R., Verma, A., Megiddo, I., Ashok, A., Laxminarayan, R., 2016. Health and economic benefits of scaling up a home-based neonatal care package in rural India: a modelling analysis. Health Policy and Planning 31, 634-644. doi:10.1093/heapol/czv113

NSSO, 2006. Morbidity, Health Care and the Condition of the Aged: NSS 60th Round. National 
Sample Survey Organisation, Ministry of Statistics and Programme Implementation, Government of India.

Parashar, U.D., Hummelman, E.G., Bresee, J.S., Miller, M.A., Glass, R.I., 2003. Global illness and deaths caused by rotavirus disease in children. Emerging Infectious Diseases 9, 565-72.

Patil, S.R., Arnold, B.F., Salvatore, A.L., Briceno, B., Ganguly, S., Colford, J.M., Gertler, P.J., 2014. The Effect of India's Total Sanitation Campaign on Defecation Behaviors and Child Health in Rural Madhya Pradesh: A Cluster Randomized Controlled Trial. PLoS Medicine 11, e1001709. doi:10.1371/journal.pmed.1001709

PIB, 2015. Nationwide Monitoring of use of Toilets will be launched from January, 2015 . Press Information Bureau, Government of India. URL http://pib.nic.in/newsite/PrintRelease.aspx?relid=114226 (accessed 10.14.15).

PIB, 2014a. Three New Vaccines Including Indigenously Developed Rotavirus Vaccine To Be Provided To All Indian Children . Press Information Bureau, Government of India. URL http://pib.nic.in/newsite/PrintRelease.aspx?relid=106055 (accessed 10.15.15).

PIB, 2014b. Restructuring of the Nirmal Bharat Abhiyan into Swachh Bharat Mission . Press Information Bureau, Government of India. URL http://pib.nic.in/newsite/PrintRelease.aspx?relid=109988 (accessed 10.14.15).

R Core Team, 2015. R: A Language and Environment for Statistical Computing. R Foundation for Statistical Computing, Vienna, Austria.

Tate, J.E., Chitambar, S., Esposito, D.H., Sarkar, R., Gladstone, B., Ramani, S., Raghava, M.V., Sowmyanarayanan, T. V, Gandhe, S., Arora, R., Parashar, U.D., Kang, G., 2009. Disease and economic burden of rotavirus diarrhoea in India. Vaccine 27 Suppl 5, F18-24. doi:10.1016/j.vaccine.2009.08.098

UN, 2015. Goal 6: Ensure access to water and sanitation for all . United Nations Sustainable Development Goal. URL http://www.un.org/sustainabledevelopment/water-and-sanitation/ (accessed 10.14.15).

UNDP, 2011. Millennium Development Goals - India Country Report 2011. United Nations Development Programme.

UNICEF, 2013. Water in India: Situations and Prospects. UNICEF, FAO and SaciWATERs, New Delhi, India.

UNICEF, 2012. Sanitation and Hygiene Advocacy and Communication Strategy Framework 2012-2017. United Nations Children's Fund and the Ministry of Drinking Water and Sanitation, Government of India, New Delhi.

Verguet, S., Laxminarayan, R., Jamison, D., 2014. Universal Public Finance of Tuberculosis Treatment in India: An Extended Cost-Effectiveness Analysis. Health Economics. doi:10.1002/hec.3019

Verguet, S., Murphy, S., Anderson, B., Johansson, K.A., Glass, R., Rheingans, R., 2013. Public finance of rotavirus vaccination in India and Ethiopia: an extended cost-effectiveness analysis. Vaccine 31, 4902-10. doi:10.1016/j.vaccine.2013.07.014 
WB, 2015. World Bank Data . World Bank, Washington D.C. URL http://databank.worldbank.org/Data/ (accessed 1.1.16).

WB, 2014. Government of India and World Bank Sign \$500 Million Agreement to Improve Rural Water Supply and Sanitation Services in Four Indian States . World Bank, New Delhi. URL http://www.worldbank.org/en/news/press-release/2014/02/07/indiagovernment-world-bank-agreement-improve-rural-water-sanitation (accessed 11.9.15).

WB, 2012. Bringing Water to Parched Indian Cities . World Bank, New Delhi. URL http://www.worldbank.org/en/news/feature/2012/07/26/bringing-water-parched-indiancities (accessed 11.9.15).

WB, 2010. A Decade of the Total Sanitation Campaign: Rapid Assessment of Processes and Outcomes. World Bank, New Delhi, India.

WHO, 2013. Diarrhoeal disease: Fact Sheet No. 330. World Health Organization, Geneva.

WHO, UNICEF, 2000. Global Water Supply and Sanitation Assessment 2000 report.

WHO/UNICEF, 2009. Diarrhoea : Why children are still dying and what can be done. World Health Organization and United Nations Children's Fund.

Wilson, S.E., Morris, S.S., Gilbert, S.S., Mosites, E., Hackleman, R., Weum, K.L.M., Pintye, J., Manhart, L.E., Hawes, S.E., 2013. Scaling up access to oral rehydration solution for diarrhea: Learning from historical experience in low- and high-performing countries. Journal of Global Health 3, 010404. doi:10.7189/jogh.03.010404

World Bank, 2012. India - Improving urban water supply and sanitation service provision (Vol. 1 of 2) : Lessons from business plans for Maharashtra, Rajasthan, Haryana and international good practices. The World Bank, New Delhi, India.

You, D., Hug, L., Ejdemyr, S., Idele, P., Hogan, D., Mathers, C., Gerland, P., New, J.R., Alkema, L., 2015. Global, regional, and national levels and trends in under-5 mortality between 1990 and 2015, with scenario-based projections to 2030: a systematic analysis by the UN Inter-agency Group for Child Mortality Estimation. Lancet. doi:10.1016/S01406736(15)00120-8 
Table 1. Disease input parameters

\begin{tabular}{|c|c|c|c|}
\hline Input & Value & Sensitivity range & Source \\
\hline Average duration of diarrheal diseases & 8 days & & $\begin{array}{c}\text { (Lamberti et } \\
\text { al., 2012) }\end{array}$ \\
\hline $\begin{array}{l}\text { Incidence of diarrheal diseases (per child } \\
\text { per year) by age }\end{array}$ & & & $\begin{array}{c}\text { (Fischer } \\
\text { Walker et al., } \\
\text { 2012) }\end{array}$ \\
\hline Under 6 months & 2.5 & $1.75-3.25$ & \\
\hline 6 months -1 year & 3.82 & $2.67-4.97$ & \\
\hline $1-2$ years & 3.09 & $2.16-4.02$ & \\
\hline $2-5$ years & 1.98 & $1.39-2.57$ & \\
\hline Average case fatality rate & 0.002 & $0.0014-0.0026$ & $\begin{array}{c}\text { (Black et al., } \\
\text { 2014) }\end{array}$ \\
\hline
\end{tabular}


Table 2. Diarrheal disease treatment input parameters

\begin{tabular}{|c|c|c|c|}
\hline Input & Value & $\begin{array}{c}\text { Sensitivity } \\
\text { range }\end{array}$ & Source \\
\hline Share of patients visiting public facilities & & & (NSSO, 2006) \\
\hline Wealth Quintile 1 & $56.63 \%$ & & \\
\hline Wealth Quintile 2 & $58.04 \%$ & & \\
\hline Wealth Quintile 3 & $61.86 \%$ & & \\
\hline Wealth Quintile 4 & $59.08 \%$ & & \\
\hline Wealth Quintile 5 & $43.53 \%$ & & \\
\hline Percentage of inpatient cases & $4.37 \%$ & & (NSSO, 2006) \\
\hline Treatment demand rate & & & (NSSO, 2006) \\
\hline Wealth Quintile 1 & $82.58 \%$ & & \\
\hline Wealth Quintile 2 & $81.02 \%$ & & \\
\hline Wealth Quintile 3 & $83.77 \%$ & & \\
\hline Wealth Quintile 4 & $90.78 \%$ & & \\
\hline Wealth Quintile 5 & $89.86 \%$ & & \\
\hline \multicolumn{4}{|l|}{ Treatment Costs } \\
\hline Inpatient seeking costs & & & $(\mathrm{NSSO}, 2006)$ \\
\hline Public & $\$ 3.35$ & $2.345-4.355$ & \\
\hline Private & $\$ 4.84$ & $3.388-6.292$ & \\
\hline \multicolumn{4}{|l|}{ Outpatient seeking costs } \\
\hline Public & $\$ 1.04$ & $0.728-1.352$ & \\
\hline Private & $\$ 1.48$ & $1.036-1.924$ & \\
\hline \multicolumn{4}{|l|}{ Inpatient treatment costs } \\
\hline Public & $\$ 24.16$ & $16.912-31.408$ & \\
\hline Private & $\$ 73.13$ & $51.191-95.069$ & \\
\hline \multicolumn{4}{|l|}{ Outpatient treatment costs } \\
\hline Public & $\$ 6.50$ & $4.550-8.450$ & \\
\hline Private & $\$ 8.09$ & $5.663-10.517$ & \\
\hline
\end{tabular}

Note: All costs are in 2013 US\$, adjusted for inflation using the gross domestic product deflator from the International Monetary Fund. Sensitivity analysis has been conducted on treatment costs. The sensitivity range is $70 \%$ to $130 \%$ of the parameter value. 
Table 3. Input parameters used for piped water supply and improved sanitation

\begin{tabular}{|c|c|c|c|}
\hline \multirow{2}{*}{$\begin{array}{l}\text { Input } \\
\begin{array}{l}\text { Reduction in relative risk of contracting } \\
\text { diarrheal diseases }\end{array}\end{array}$} & Value & Sensitivity range & Source \\
\hline & & & \multirow{4}{*}{ (Fewtrell et al., 2005) } \\
\hline Piped water alone & 0.25 & $0.18-0.33$ & \\
\hline Improved sanitation alone & 0.32 & $0.22-0.42$ & \\
\hline Both piped water and improved sanitation & 0.33 & $0.23-0.43$ & \\
\hline \multicolumn{3}{|c|}{ Average piped water supply investment cost (per capita) } & $\begin{array}{c}\text { (Hutton and Bartram, } \\
\text { 2008; Hutton, 2013, 2012) }\end{array}$ \\
\hline Wealth Quintile 1 & $\$ 89$ & $\$ 62-\$ 116$ & \\
\hline Wealth Quintile 2 & $\$ 157$ & $\$ 110-\$ 204$ & \\
\hline Wealth Quintile 3 & $\$ 157$ & $\$ 110-\$ 204$ & \\
\hline Wealth Quintile 4 & $\$ 170$ & $\$ 119-\$ 221$ & \\
\hline Wealth Quintile 5 & $\$ 203$ & $\$ 142-\$ 264$ & \\
\hline \multicolumn{2}{|l|}{ Piped water baseline coverage } & & \multirow{6}{*}{ (IIPS, 2010) } \\
\hline Wealth Quintile 1 & 0.04 & & \\
\hline Wealth Quintile 2 & 0.15 & & \\
\hline Wealth Quintile 3 & 0.32 & & \\
\hline Wealth Quintile 4 & 0.46 & & \\
\hline Wealth Quintile 5 & 0.69 & & \\
\hline \multicolumn{2}{|l|}{ Average sanitation investment cost (per capita) } & & $\begin{array}{c}\text { (Hutton and Bartram, } \\
\text { 2008; Hutton, 2013, 2012) }\end{array}$ \\
\hline Wealth Quintile 1 & $\$ 91$ & $\$ 64-\$ 118$ & \\
\hline Wealth Quintile 2 & $\$ 195$ & $\$ 137-\$ 254$ & \\
\hline Wealth Quintile 3 & $\$ 213$ & \$149-\$277 & \\
\hline Wealth Quintile 4 & $\$ 261$ & $\$ 183-\$ 339$ & \\
\hline Wealth Quintile 5 & $\$ 429$ & $\$ 300-\$ 558$ & \\
\hline Sanitation baseline coverage & & & (IIPS, 2010) \\
\hline Wealth Quintile 1 & 0.00 & & \\
\hline Wealth Quintile 2 & 0.07 & & \\
\hline Wealth Quintile 3 & 0.23 & & \\
\hline Wealth Quintile 4 & 0.58 & & \\
\hline Wealth Quintile 5 & 0.94 & & \\
\hline
\end{tabular}

Note: The sensitivity range is $70 \%$ to $130 \%$ of the parameter value. Piped water supply is defined as either a tap in the household premises or a public tap nearby. Improved sanitation includes connection to a public sewer, connection to a septic system, pour-flush latrine, pit latrine, and ventilated improved pit latrine. Cost estimates are based on Hutton $(2012,2013)$ and Hutton and Bartram (2008). Per capita cost in each quintile is derived on the basis of scaling up ( $95 \%$ coverage at random) the different types of water or sanitation facility according to the distribution in the baseline. All estimates are adjusted to 2013 US $\$$ using the gross domestic product deflator from the International Monetary Fund. 
Table 4. Incremental health outcomes (per 100,000 under-five children) of interventions, by wealth quintile

\begin{tabular}{|c|c|c|c|c|c|}
\hline \multirow[t]{2}{*}{ Outcome } & \multirow[t]{2}{*}{$\begin{array}{l}\text { Wealth } \\
\text { quintile }\end{array}$} & \multicolumn{2}{|c|}{$\begin{array}{c}\text { 95\% coverage at random } \\
\text { Intervention } 1\end{array}$} & \multicolumn{2}{|c|}{$\begin{array}{c}\text { At least } 95 \% \text { coverage in each } \\
\text { state } \\
\text { Intervention } 2\end{array}$} \\
\hline & & Value & $95 \%$ UR & Value & $95 \%$ UR \\
\hline \multirow{6}{*}{$\begin{array}{l}\text { Diarrheal } \\
\text { disease } \\
\text { incidence } \\
\text { averted }\end{array}$} & I & 69,148 & $67,556-70,739$ & 70,173 & $68,329-72,017$ \\
\hline & II & 59,931 & $58,369-61,493$ & 60,336 & $58,725-61,947$ \\
\hline & III & 45,383 & $44,064-46,703$ & 45,737 & $44,315-47,160$ \\
\hline & IV & 25,817 & $24,914-26,719$ & 25,202 & $24,167-26,238$ \\
\hline & $\mathrm{V}$ & 3,511 & $2,838-4,185$ & 3,362 & $2,712-4,013$ \\
\hline & Overall & 43,126 & $42,085-44,167$ & 43,352 & 42,201-44,504 \\
\hline \multirow{6}{*}{$\begin{array}{l}\text { Deaths } \\
\text { averted }\end{array}$} & $\mathrm{I}$ & 105 & $91-118$ & 113 & $101-126$ \\
\hline & II & 95 & $81-109$ & 92 & $77-107$ \\
\hline & III & 69 & $55-82$ & 70 & $56-84$ \\
\hline & IV & 44 & $31-56$ & 35 & $22-49$ \\
\hline & $\mathrm{V}$ & 10 & $0-24$ & 11 & $0-21$ \\
\hline & Overall & 68 & $61-74$ & 68 & $62-74$ \\
\hline
\end{tabular}

Notes: Estimates are for 100,000 under-five children in each wealth quintile. The overall estimates are for 100,000 under-five children in the overall study population. UR = uncertainty range, which is estimated from sensitivity analysis using a Latin hypercube sampling method (100 simulations). The outcomes are incremental to the baseline. 
Table 5. Incremental financial outcomes (per 100,000 under-five children) of interventions, by wealth quintile

\begin{tabular}{|c|c|c|c|c|c|}
\hline \multirow[t]{2}{*}{ Outcome } & \multirow[t]{2}{*}{$\begin{array}{l}\text { Wealth } \\
\text { quintile }\end{array}$} & \multicolumn{2}{|c|}{$\begin{array}{l}\text { 95\% coverage at random } \\
\text { Intervention } 1\end{array}$} & \multicolumn{2}{|c|}{$\begin{array}{c}\text { At least } 95 \% \text { coverage in each state } \\
\text { Intervention } 2\end{array}$} \\
\hline & & Value & $95 \%$ UR & Value & $95 \%$ UR \\
\hline \multirow{6}{*}{$\begin{array}{l}\text { Out-of-pocket } \\
\text { expenditure } \\
\text { averted }\end{array}$} & I & $\$ 586,765$ & $\$ 568,419-\$ 605,111$ & $\$ 596,952$ & $\$ 576,967-\$ 616,936$ \\
\hline & II & $\$ 483,066$ & $\$ 466,885-\$ 499,246$ & $\$ 487,151$ & $\$ 470,267-\$ 504,034$ \\
\hline & III & $\$ 347,481$ & $\$ 334,380-\$ 360,583$ & $\$ 351,343$ & $\$ 337,708-\$ 364,977$ \\
\hline & IV & $\$ 226,248$ & $\$ 215,912-\$ 236,583$ & $\$ 219,744$ & $\$ 208,500-\$ 230,989$ \\
\hline & $\mathrm{V}$ & $\$ 36,530$ & $\$ 27,087-\$ 45,973$ & $\$ 33,799$ & $\$ 25,231-\$ 42,367$ \\
\hline & Overall & $\$ 355,681$ & 344,374-\$366,987 & $\$ 357,788$ & $\$ 345,509-\$ 370,067$ \\
\hline \multirow{6}{*}{$\begin{array}{l}\text { Incremental } \\
\text { cost to } \\
\text { government }\end{array}$} & I & $\$ 3,198,001$ & $\$ 3,144,516-\$ 3,251,486$ & $\$ 3,298,963$ & $\$ 3,243,117-\$ 3,354,810$ \\
\hline & II & $\$ 5,819,261$ & $\$ 5,718,834-\$ 5,919,687$ & $\$ 5,427,958$ & $\$ 5,336,544-\$ 5,519,372$ \\
\hline & III & $\$ 5,245,987$ & $\$ 5,146,406-\$ 5,345,569$ & $\$ 4,900,775$ & $\$ 4,807,938-\$ 4,993,613$ \\
\hline & IV & $\$ 3,957,290$ & $\$ 3,848,604-\$ 4,065,976$ & $\$ 3,845,672$ & $\$ 3,739,619-\$ 3,951,726$ \\
\hline & $\mathrm{V}$ & $\$ 1,470,011$ & $\$ 1,384,173-\$ 1,555,849$ & $\$ 1,569,839$ & $\$ 1,478,747-\$ 1,660,932$ \\
\hline & Overall & $\$ 4,031,839$ & $\$ 3,953,651-\$ 4,110,028$ & $\$ 3,896,542$ & $\$ 3,821,691-\$ 3,971,393$ \\
\hline \multirow{6}{*}{$\begin{array}{l}\text { Value of } \\
\text { insurance }\end{array}$} & I & $\$ 7,125$ & $\$ 6,950-\$ 7,301$ & $\$ 7,185$ & $\$ 7,002-\$ 7,367$ \\
\hline & II & $\$ 4,169$ & $\$ 4,056-\$ 4,281$ & $\$ 4,191$ & $\$ 4,079-\$ 4,302$ \\
\hline & III & $\$ 2,119$ & $\$ 2,058-\$ 2,180$ & $\$ 2,113$ & $\$ 2,051-\$ 2,174$ \\
\hline & IV & $\$ 776$ & \$753-\$799 & $\$ 770$ & $\$ 745-\$ 795$ \\
\hline & $\mathrm{V}$ & $\$ 64$ & $\$ 54-\$ 73$ & $\$ 66$ & $\$ 57-\$ 74$ \\
\hline & Overall & $\$ 1,640$ & $\$ 1,598-\$ 1,681$ & $\$ 1,646$ & $\$ 1,603-\$ 1,689$ \\
\hline
\end{tabular}

Notes: Estimates are for 100,000 under-five children in each wealth quintile. The overall estimates are for per 100,000 under-five children in the overall study population. UR = uncertainty range, which is estimated from sensitivity analysis using a Latin hypercube sampling method (100 simulations). The outcomes are incremental to the baseline. All estimates are in 2013 US\$, assuming US $\$ 1$ = INR 60.936 (US Treasury average exchange rate for 2013) and using the gross domestic product deflator from the International Monetary Fund. 
Figure 1. Geographic distribution of piped water supply coverage at baseline

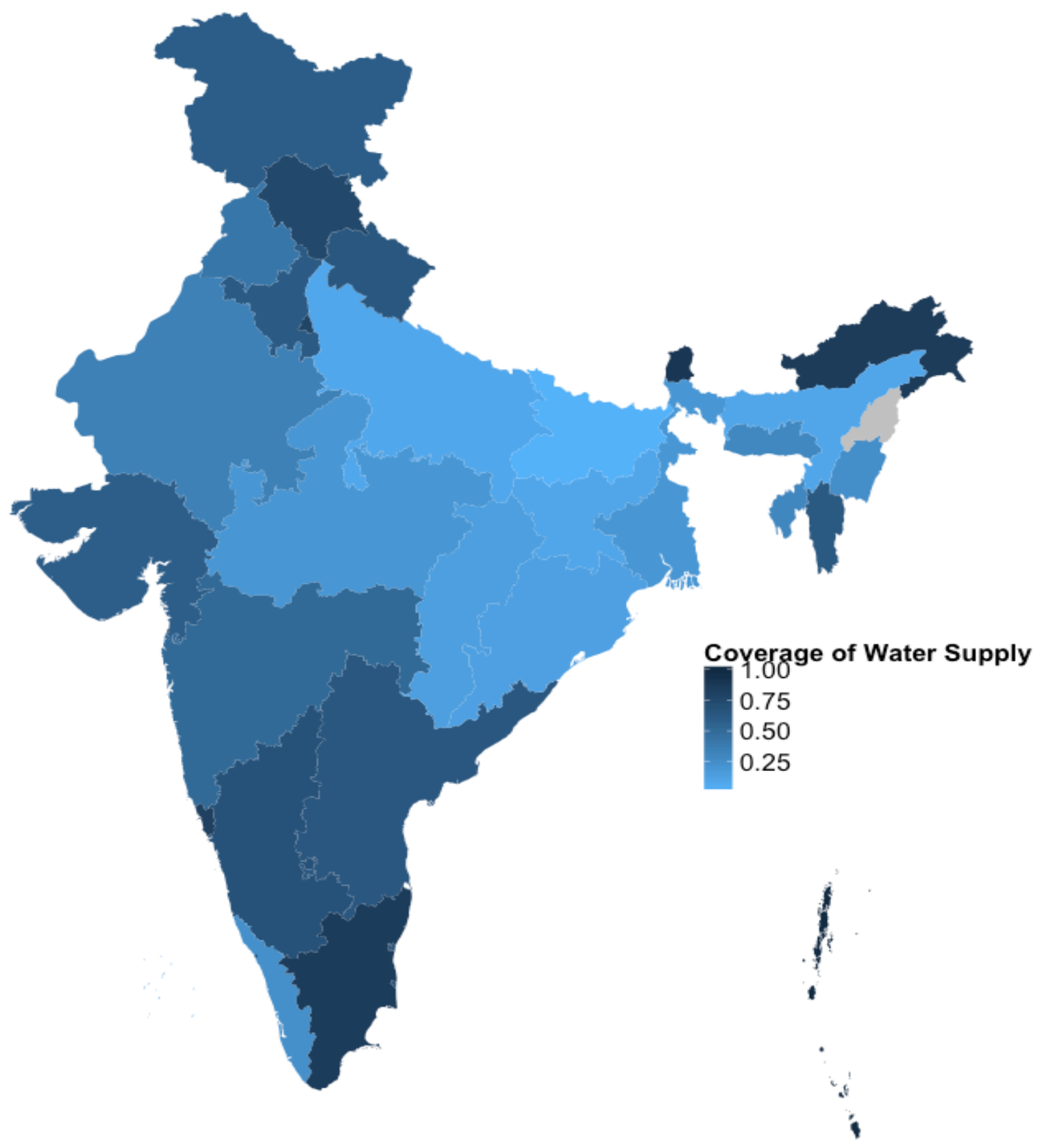

Note: Data are from the DLHS-3 (2007-2008). Graph shows the percentage of households in each state with access to one of the following types of piped water supply - piped into dwelling, piped to yard/plot, and public tap/standpipe. 


\section{Figure 2. Geographic distribution of improved sanitation coverage at baseline}

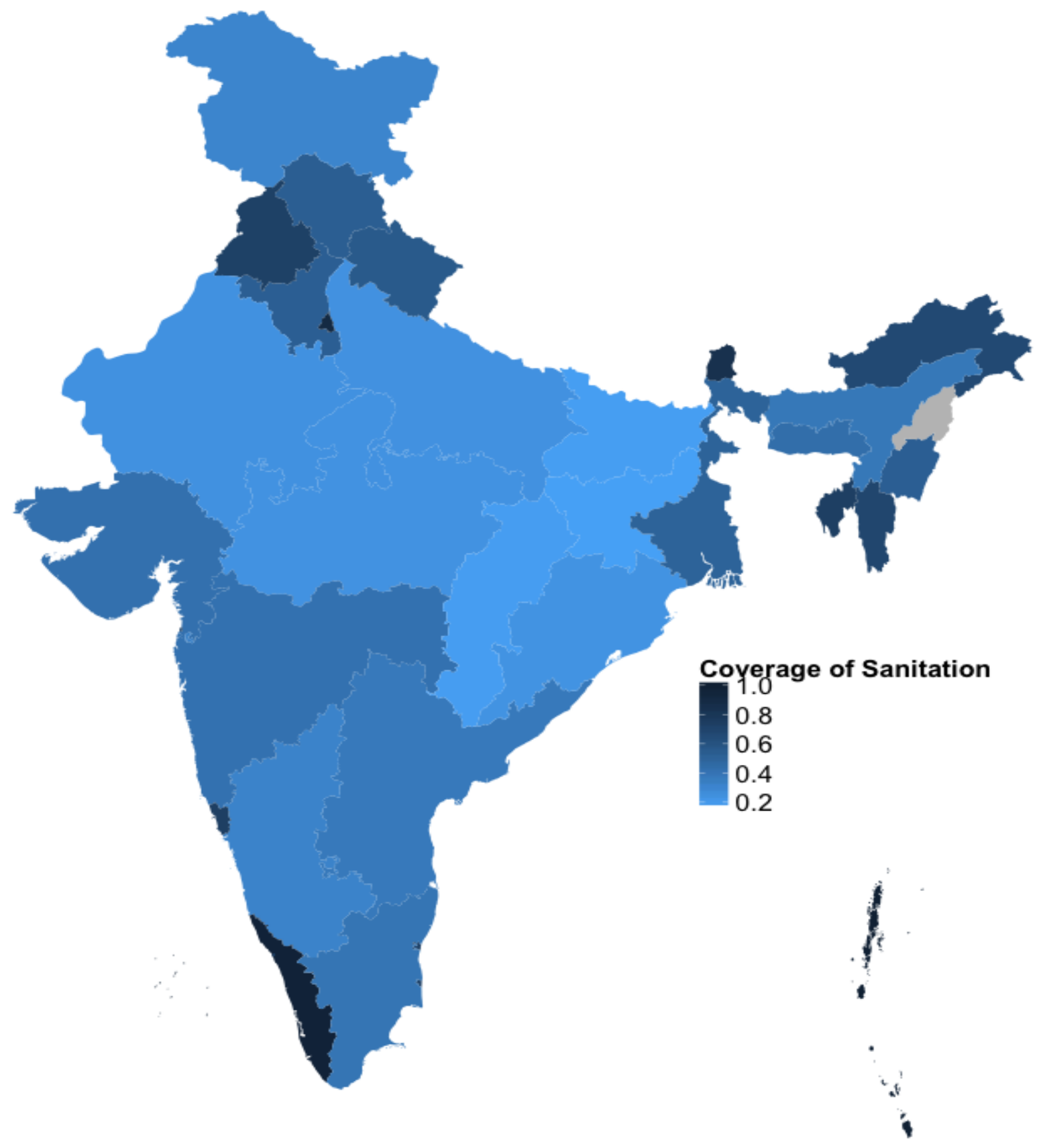

Note: Data are from the DLHS-3 (2007-2008). Graph shows the percentage of households in each state with access to one of the following types of toilet - public sewer, septic system, pour-flush latrine, simple pit latrine, or ventilated improved pit latrine. 
Figure 3. Geographic distribution of health outcomes per 100,000 under-five children per year
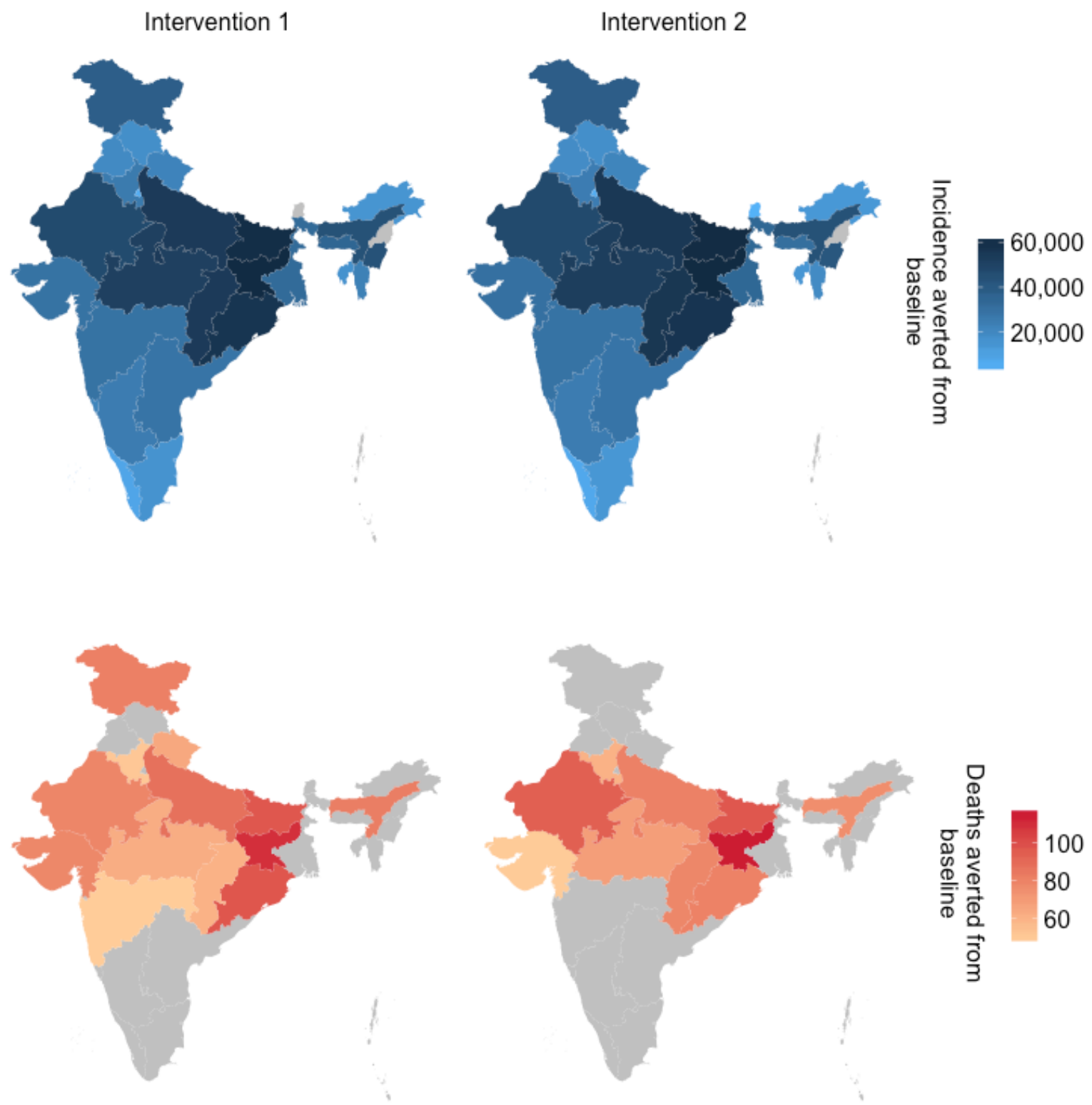

Note: Nagaland is excluded from our analysis because it was not covered by DLHS-3. States in which the benefits of the intervention are negligible are marked in grey. 
Figure 4. Geographic distribution of out-of-pocket (OOP) expenditures and financial risk protection per 100,000 under-five children per year
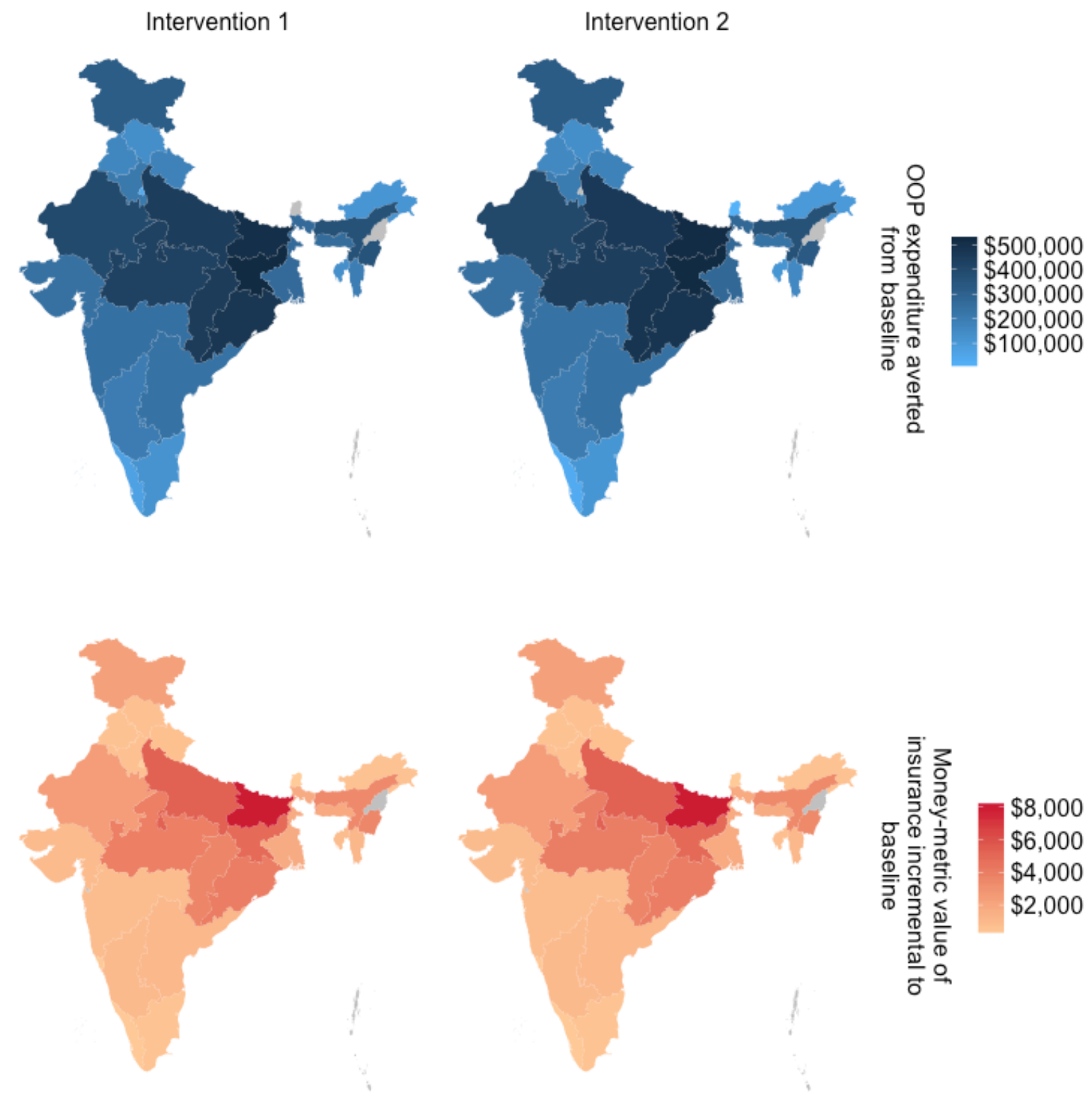

Note: Nagaland is excluded from our analysis because it was not covered by DLHS-3. 